\title{
Investigação dos principais processos de corrosão em estações de energia elétrica do Estado do RS
}

\author{
RIEDER $^{\mathrm{I}}$, E.S.; BRUSAMARELLO ${ }^{\mathrm{II}}$, V.; BIANCHI ${ }^{\mathrm{I}}$, A.L; BALBINOT ${ }^{\mathrm{II}}$, A. \\ ${ }^{\mathrm{I}}$ Programa de Pós-Graduação em Engenharia, PPGEAM, \\ ULBRA, Canoas, Rio Grande do Sul, Brasil. Tel: +55 5134779285 \\ II Departamento de Engenharia Elétrica, UFRGS
}

e-mail: esterrieder@terra.com.br, brusamarello.valner@gmail.com, andre.luis.bianchi@gmail.com, abalbinot@gmail.com

\begin{abstract}
RESUMO
Este estudo investigou os principais agentes de corrosão em quatro subestações de energia elétrica do estado do Rio Grande do Sul, três no litoral e uma em Porto Alegre. O objetivo foi determinar as taxas de corrosão de vários materiais metálicos expostos aos agentes agressivos existentes no ambiente das subestações. Foram desenvolvidos experimentos de perda de massa dos materiais expostos em tempo real nas subestações, monitoramento de potencial do solo, determinação da composição química e resistividade do solo, e análise micrográfica e química dos materiais após exposição no sítio de trabalho. Os ensaios de perda de massa foram realizados seguindo as normas ISO (International Organization of Standardization) 8407, 8565 e 9223 a 9227. A resistividade do solo foi determinada pelo método Wenner e as micrografias e constituição química dos produtos de corrosão por microscopia eletrônica de varredura e espectroscopia de energia dispersiva, respectivamente. Resultados mostraram significativa alteração nas massas do aço e do cobre, principalmente nas subestações litorâneas. Embora os agentes corrosivos existam no solo, as altas taxas de corrosão no litoral estão fortemente associadas à maresia. Já para o zinco e o aço galvanizado, a corrosão foi mais expressiva em Porto Alegre, região urbana sem presença de maresia. Os solos de todas as subestações estudadas apresentaram alta resistividade, o que implica em baixa agressividade destes aos materiais metálicos. Com estas conclusões, fica evidente que os procedimentos e precauções em relação à corrosão dos componentes metálicos das subestações expostas a condições extremas de agressividade, como em presença de íons cloreto e particulados sólidos, não podem ser os mesmos que os adotados para os ambientes livres destes componentes.
\end{abstract}

Palavras-chave: corrosão, ensaio de corrosão, estação energia elétrica, resistividade do solo, potencial do solo.

\section{Investigation of the main corrosion processes on electrical energy} stations of the state of Rio Grande do Sul - Brasil

\section{ABSTRACT}

This study investigated the main corrosion agents in four electric energy station in the state of Rio Grande do Sul, three on the coast and one in Porto Alegre (capital of Rio Grande do Sul). The objective was to determine the corrosion rates of various metallic materials exposed to the aggressive agents present in the stations atmosphere. Loss mass experiments of the materials exposed in real time in the electric stations, soil potential monitoring, soil resistivity measurement, soil chemical analysis, and micrographic and chemical analysis of the materials after exposure in the study sites were performed. The loss mass experiments were performed using the International Organization of Standardization, ISO, 8407, 8565 e 9223 a 9227. The soil resistivity was determined using the Wenner method and the micrographs and chemical analysis of the corrosion products were obtained using scanning electron microscopy and energy dispersive spectroscopy, respectively. Results showed significant change in the mass of steel and cooper, mainly in the stations located on the coast. Although the corrosive agents are present in the soil, the high corrosion rates on the coast were strongly associated with the marine atmosphere. All station soils presented high resistivity, which implies low aggressiveness to metallic materials. With these conclusions, it is evident that the procedures and precautions related to corrosion of the metallic components exposed to conditions of extreme aggressiveness, 
such as those in the presence of chloride ions and solid particulates, cannot be the same as the ones used for the atmospheres free of these components.

Keywords: corrosion, corrosion test, electric station, soil resistance, soil potential.

\section{INTRODUÇÃO}

A corrosão de componentes metálicos em grandes empreendimentos e instalações, como os sistemas de transmissão e distribuição de energia elétrica, resulta em prejuízos econômicos decorrentes de reposições de peças e paradas de processo. Brusamarello et al. [1] apontam que países industrializados como os EUA apresentam prejuízos da ordem de 300 bilhões de dólares anuais, superando catástrofes como enchentes e fogo naquele mesmo país. Com relação ao Brasil, apesar de não existirem estudos completos sobre os prejuízos causados pela corrosão, é possível fazer-se uma estimativa, utilizando-se um estudo global feito pelo Comitê T.P. Hoar, onde o custo da corrosão para um país industrializado é de aproximadamente 3,5\% do seu PIB. Estima-se que no Brasil os prejuízos decorrentes da corrosão ultrapassem 30 bilhões de dólares anuais.

As causas da corrosão, que originam a deterioração, no entanto, são diversas. A problemática da corrosão em plantas de sistemas elétricos é bem documentado [2-6]. Falhas de componentes da planta representam custos envolvidos com a paralisação do sistema e com reposição dos mesmos. Estudos sobre as causas da corrosão, sua velocidade e mecanismos envolvidos nos diferentes sistemas metal-meio ambiente, são determinantes para estender a vida útil dos materiais. Estudos de corrosão atmosférica específicos em uma determinada região tem sido reportados [ㄱ-12].

Este estudo desenvolveu experimentos em quatro subestações de energia elétrica com o objetivo de determinar as taxas de corrosão de diferentes materiais metálicos expostos aos agentes agressivos dos meios em que as subestações estão inseridas, bem como de determinar os mecanismos de ataque corrosivo nestes materiais, visando a otimização de seu uso.

\section{MATERIAIS E MÉTODOS}

\subsection{Ensaios atmosféricos de perda de massa}

Foram realizados ensaios atmosféricos de perda de massa em tempo real nas estações de acordo com as normas ISO 8407, 8565, 9223, 9224, 9225, 9226 e 9227 [13-19]. Tais ensaios foram realizados sob condições análogas às de serviço, permitindo, portanto, uma avaliação fidedigna da ação do meio corrosivo sobre o material metálico. Foram construídos bastidores em madeira para suporte das peças, segundo a norma ISO 9225, com capacidade para 36 corpos-de-prova, 9 de cada material. Nos bastidores foram posicionadas as amostras com suportes de alumínio anodizado e isolantes poliméricos, os quais garantem o isolamento das peças, evitando o contato e sobreposição de peças vizinhas.

Os materiais utilizados para a realização dos ensaios de corrosão foram os estabelecidos pela norma ISO 9226 [13]: aço carbono, zinco, cobre, alumínio e aço galvanizado (este acrescentado ao projeto, por ter grande inserção nas plantas das subestações), com grau de pureza determinado em 99,73\%, 99,3\%, 99,98\% e $99,3 \%$, respectivamente. As espessuras das peças foram 0,80, 5,00, 1,08, 1,00 e 1,95 mm, respectivamente.

Os locais de realização dos ensaios de corrosão em tempo real foram definidos com o auxílio de membros da companhia de distribuição. Quatro subestações foram determinadas, três no litoral, onde a corrosão é intensa e com demanda frequente manutenção e substituição de peças, e uma em atmosfera moderada sem influência do ambiente marítimo, localizada em Porto Alegre.

Em Porto Alegre foi selecionada a subestação PAL3, situada em região com contribuições atmosféricas pouco agressivas. Já no litoral, foram selecionadas subestações, que de acordo com membros da companhia, apresentavam os maiores problemas de corrosão: Subestação PIN, no município de Pinhal; Subestação ATL, em Capão da Canoa; e Subestação OSO1, na cidade de Osório. 
As estruturas instaladas nas subestações podem ser visualizadas na Figura 1.

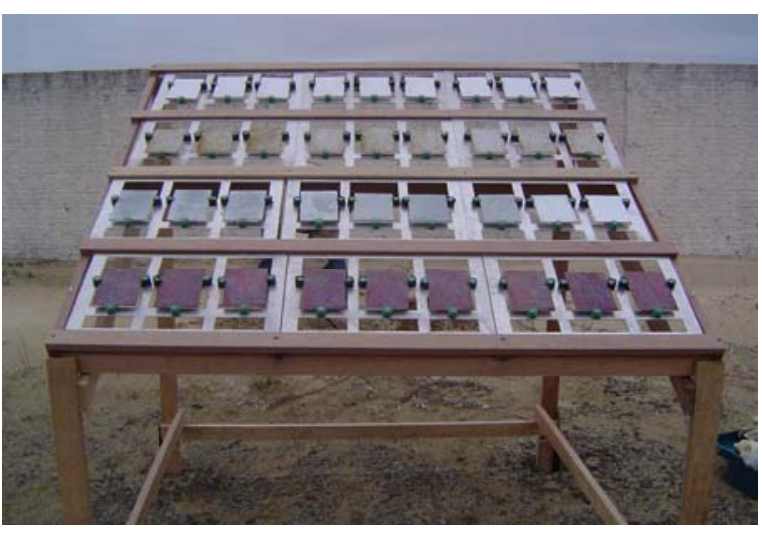

a)

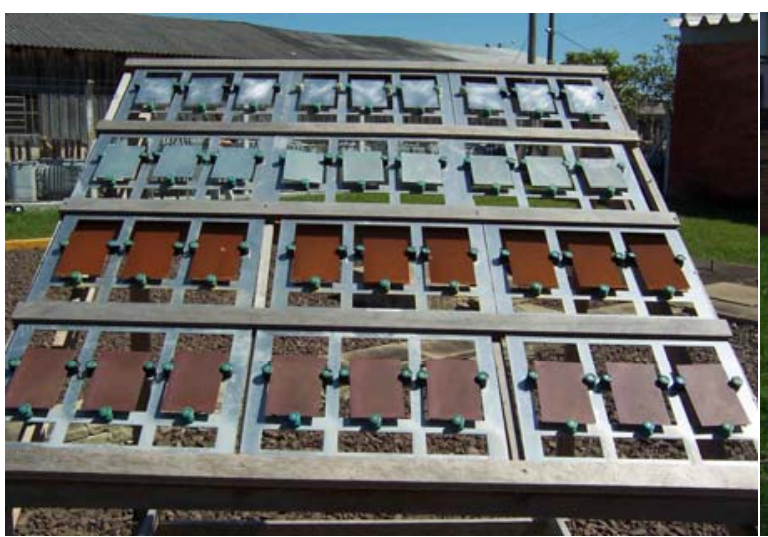

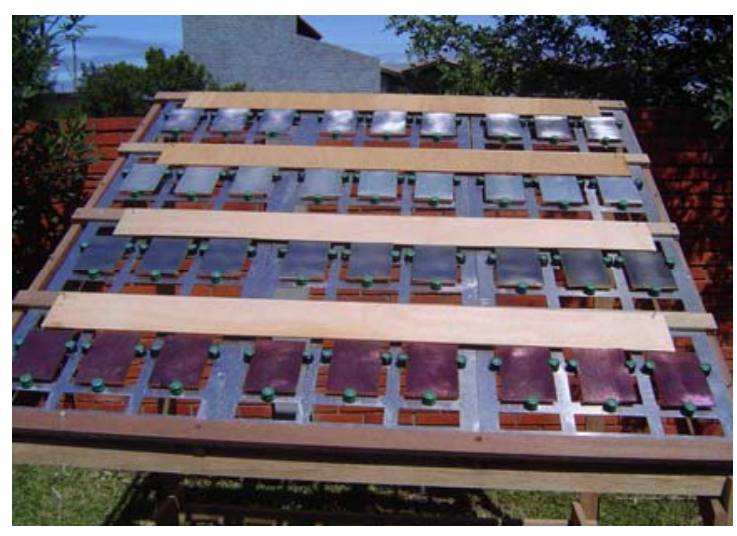

b)

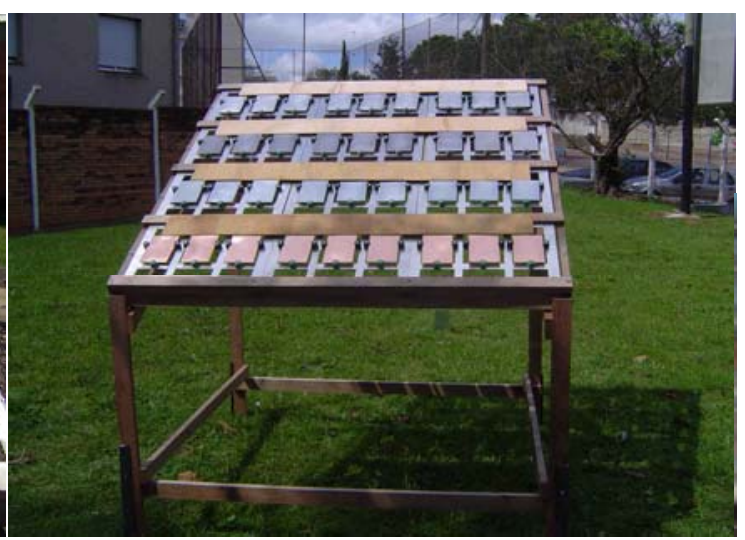

c)

d)

Figura 1: Bastidores com amostras nas subestações a) PIN, b) ATL, c) OSO1 e d) PAL3.

A preparação dos corpos-de-prova, antes da exposição nas diferentes atmosferas, foi realizada de acordo com a norma ISO 8565. Os materiais, obtidos de um mesmo lote (para cada tipo de material), foram cortados nas dimensões 150 mm x 100 mm (sugestão da norma) e numeradas por estampagem manual, permitindo a legibilidade durante todo o período de exposição.

Os corpos-de-prova foram limpos antes e após os ensaios de campo e de laboratório (câmara de névoa salina). A primeira etapa do processo de limpeza consistiu em lavagem com desengraxante para remoção de óleos e graxas.

Na segunda etapa do processo procedeu-se com a imersão das peças em reagentes químicos, específicos para cada tipo de material, segundo norma ISO 8407-91. Esta norma estabelece que a limpeza, após os ensaios de corrosão deve ser feita de forma seqüencial em vários estágios para a remoção lenta dos produtos de corrosão, de modo a construir uma curva que facilita a obtenção da massa real de material atacado por processos corrosivos. Os reagentes e condições de limpeza estão especificados na Tabela 1. 
RIEDER, E. S.; BRUSAMARELLO, V.; BIANCHI, A.L.; BALBINOT, A.; Revista Matéria, v. 14, n. 3, pp. 1000 - $1014,2009$.

Tabela 1: Condições de Limpeza dos Corpos-de-prova.

\begin{tabular}{c|c|l}
\hline Material & Reagente Químico & \multicolumn{1}{c}{ Condições } \\
\hline Aço & $\mathrm{HCl} 50 \%+0,35 \% \mathrm{C}_{6} \mathrm{H}_{12} \mathrm{~N}_{4}$ & temperatura ambiente, tempo de exposição: 1 min. \\
\hline Cobre & $\mathrm{H}_{2} \mathrm{SO}_{4} 10 \%$ & temperatura ambiente, tempo de exposição: 5 min. \\
\hline Zinco & $\mathrm{CH}_{3} \mathrm{COONH}_{4} 10 \%$ & temperatura $70^{\circ} \mathrm{C}$, tempo de exposição: 2 a 5 min. \\
\hline Alumínio & $\mathrm{HNO}_{3} 65 \%$ & temperatura ambiente, tempo de exposição: 1 a 5 min. \\
\hline Aço galvanizado & $\mathrm{CH}_{3} \mathrm{COONH}_{4} 10 \%$ & temperatura $70^{\circ} \mathrm{C}$, tempo de exposição: 2 a 5 min. \\
\hline
\end{tabular}

Após a limpeza dos corpos-de-prova, verificou-se a perda de massa, subtraindo-se do seu peso original a massa após o ensaio. Como a perda de massa é influenciada pela área exposta e tempo de exposição, essas variáveis são combinadas e expressas em taxa de corrosão [20,21,22], conforme a expressão:

$$
\text { Taxa de Corrosão }=\frac{\Delta \mathrm{m}}{\mathrm{A} \cdot \mathrm{t}}
$$

Onde: $\quad \Delta \mathrm{m} \quad$ é a perda de massa, em grama;

A é a área superficial, em metro quadrado e

t $\quad$ é o tempo de exposição, em anos

A taxa de corrosão é expressa em grama por metro quadrado ano [g.m $\mathrm{m}^{-2} \cdot \mathrm{a}^{-1}$.

\subsection{Características do solo - potencial e resistividade}

O monitoramento do potencial do solo fornece informações sobre a agressividade do solo em relação à corrosão. As medidas foram realizadas com eletrodos de aço galvanizado, os quais foram enterrados cerca de $0,5 \mathrm{~m}$ no solo dentro dos limites das subestações. O eletrodo de referência utilizado foi o Eletrodo de Calomelano Saturado (ECS).

Nos sites das subestações também determinou-se a resistividade do solo, utilizando-se o método das quatro pontas (método Wenner) com eletrodos de aço cobreados, tipo barras cooperweld com diâmetro de $12,5 \mathrm{~mm}$ e comprimento $0,7 \mathrm{~m}$ e um medidor de resistividade. As quatro hastes foram enterradas $0,5 \mathrm{~m}$ no solo a uma distância de $1,5 \mathrm{~m}$.

Foram ainda realizadas análises químicas dos agentes agressores de maior importância para a corrosão nos solos das subestações, enxofre total e cloreto.

\subsection{Análise da morfologia superficial e análise química de superfície}

Para caracterização da morfologia superficial das peças, após a ação das intempéries por 90 dias de exposição nas subestações do litoral e 83 dias na estação de Porto Alegre, as peças foram micrografadas por Microscopia Eletrônica de Varredura - MEV.

A composição química dos depósitos, formados por processos de oxidação do material metálico, foi realizada por Espectroscopia de Energia Dispersiva (EDS). Esta análise forneceu resultados semiquantitativos dos elementos presentes na superfície. As amostras analisadas foram as mesmas visualizadas previamente por Microscopia Eletrônica de Varredura.

\section{RESULTADOS E DISCUSSÃo}

\subsection{Ensaios atmosféricos de perda de massa}

Segundo as normas ISO citadas neste trabalho, os ensaios para perda de massa são de longo prazo, mínimo de um ano. Quanto aos parâmetros para avaliação da corrosão atmosférica, a norma ISO 9223:1992 apresenta uma classificação por categorias, sendo: C1, muito baixa; C2, baixa; C3, média; C4, alta; e C5, muito alta. Como a norma não apresenta tabela referência para o aço zincado, que também foi utilizado no estudo, a avaliação desta se deu através do emprego dos parâmetros para a avaliação do zinco.

Sendo assim, este trabalho traz uma avaliação da exposição de doze meses para os corpos-de-prova colocados nas subestações de Osório, Atlântida e Pinhal e treze meses para os corpos-de-prova de Porto 
RIEDER, E. S.; BRUSAMARELLO, V.; BIANCHI, A.L.; BALBINOT, A.; Revista Matéria, v. 14, n. 3, pp. 1000 - $1014,2009$.

Alegre. Através dos dados de perda de massa, foram determinadas as taxas de corrosão para o período de exposição nas subestações PAL3, ATL, OSO1 e PIN. Os resultados estão resumidos na Tabela 2.

Tabela 2: Taxas de Corrosão para os Três Primeiros Meses de Exposição.

\begin{tabular}{|c|c|c|}
\hline & Média das taxas de corrosão ( $\left.\mathrm{g} / \mathrm{m}^{2} \mathrm{ano}\right)$ & Classificação (ISO 9223) \\
\hline \multicolumn{3}{|c|}{ Aço } \\
\hline OSO1 & 411,244 & $\mathrm{C} 4$ \\
\hline ATL & 597,200 & C4 \\
\hline PIN & 696,822 & $\mathrm{C} 5$ \\
\hline PAL3 & 308,433 & C3 \\
\hline $\begin{array}{l}\text { Média segundo } \\
\text { norma }\end{array}$ & $\begin{array}{ll}\text { taxa corrosão } \leq 10 & \rightarrow \text { C1 } \\
10<\text { taxa corrosão } \leq 200 & \rightarrow \text { C2 } \\
200<\text { taxa corrosão } \leq 400 \rightarrow \text { C3 } \\
\end{array}$ & $\begin{array}{l}400<\text { taxa corrosão } \leq 650 \rightarrow \text { C4 } \\
650<\text { taxa corrosão } \leq 1500 \rightarrow \text { C5 }\end{array}$ \\
\hline \multicolumn{3}{|c|}{$\begin{array}{ll} & \text { Cobre } \\
\end{array}$} \\
\hline OSO1 & 23,822 & $\mathrm{C} 4$ \\
\hline ATL & 47,778 & $\mathrm{C} 5$ \\
\hline PIN & 113,578 & Extrapolou \\
\hline PAL3 & 10,219 & C3 \\
\hline $\begin{array}{l}\text { Média segundo } \\
\text { norma }\end{array}$ & $\begin{array}{ll}\text { taxa corrosão } \leq 0,9 & \rightarrow \mathrm{C} 1 \\
0,9<\text { taxa corrosão } \leq 5 & \rightarrow \mathrm{C} 2 \\
5<\text { taxa corrosão } \leq 12 & \rightarrow \mathrm{C} 3 \\
\end{array}$ & $\begin{array}{ll}12<\text { taxa corrosão } \leq 25 & \rightarrow \text { C4 } \\
25<\text { taxa corrosão } \leq 50 & \rightarrow \text { C5 }\end{array}$ \\
\hline \multicolumn{3}{|c|}{ Zinco } \\
\hline OSO1 & 8,167 & C3 \\
\hline ATL & 15,933 & $\mathrm{C} 4$ \\
\hline PIN & 19,100 & $\mathrm{C} 4$ \\
\hline PAL3 & 4,155 & $\mathrm{C} 2$ \\
\hline $\begin{array}{l}\text { Média segundo } \\
\text { norma }\end{array}$ & $\begin{array}{ll}\text { taxa corrosão } \leq 0,7 & \rightarrow \mathrm{C} 1 \\
0,7<\text { taxa corrosão } \leq 5 & \rightarrow \mathrm{C} 2 \\
5<\text { taxa corrosão } \leq 15 & \rightarrow \mathrm{C} 3 \\
\end{array}$ & $\begin{array}{ll}15<\text { taxa corrosão } \leq 30 & \rightarrow \mathrm{C} 4 \\
30<\text { taxa corrosão } \leq 60 & \rightarrow \mathrm{C} 5\end{array}$ \\
\hline \multicolumn{3}{|c|}{$\begin{aligned} & \text { Alumínio } \\
&\end{aligned}$} \\
\hline OSO1 & 0,853 & C3 \\
\hline ATL & 1,600 & C3 \\
\hline PIN & 2,200 & C4 \\
\hline PAL3 & 0,385 & $\mathrm{C} 2$ \\
\hline $\begin{array}{l}\text { Média segundo } \\
\text { norma }\end{array}$ & \begin{tabular}{|ll} 
desconsiderável & $\rightarrow \mathrm{C} 1$ \\
taxa corrosão $\leq 0,6$ & $\rightarrow \mathrm{C} 2$ \\
$0,6<$ taxa corrosão $\leq 2$ & $\rightarrow \mathrm{C} 3$ \\
\end{tabular} & $\begin{array}{ll}2<\text { taxa corrosão } \leq 5 & \rightarrow \text { C4 } \\
5<\text { taxa corrosão } \leq 60 & \rightarrow \text { C5 }\end{array}$ \\
\hline & Aço Zincado (Galvaniza & \\
\hline OSO1 & 10,733 & C3 \\
\hline ATL & 13,333 & C3 \\
\hline PIN & 22,867 & $\mathrm{C} 4$ \\
\hline PAL3 & 9,110 & C3 \\
\hline $\begin{array}{l}\text { Média segundo } \\
\text { norma }\end{array}$ & $\begin{array}{ll}\text { taxa corrosão } \leq 0,7 & \rightarrow \mathrm{C} 1 \\
0,7<\text { taxa corrosão } \leq 5 & \rightarrow \mathrm{C} 2 \\
5<\text { taxa corrosão } \leq 15 & \rightarrow \mathrm{C} 3 \\
\end{array}$ & $\begin{array}{ll}15<\text { taxa corrosão } \leq 30 & \rightarrow \mathrm{C} 4 \\
30<\text { taxa corrosão } \leq 60 & \rightarrow \mathrm{C} 5\end{array}$ \\
\hline
\end{tabular}

As taxas de corrosão do aço nas subestações, de acordo com a norma, apresentaram índices altos a muito altos, com exceção da estação de Porto Alegre, que apresentou um índice médio.

Para o cobre, as taxas de corrosão das subestações ATL e PIN foram muito altas, sendo que a taxa desta última extrapolou os limites estabelecidos pela norma. As subestações OSO1 e PAL3 apresentaram taxas altas e médias, respectivamente.

O zinco mostrou-se menos susceptível à corrosão atmosférica nas subestações PAL3 e OSO1, com classificação baixa e média, respectivamente. Assim como para o aço, o zinco apresentou taxas de corrosão altas para as subestações ATL e PIN.

O alumínio apresentou taxas de corrosão médias para as subestações OSO1 e ATL, baixa para PAL3 e alta para a subestação PIN. 
O aço zincado apresentou taxa de corrosão atmosférica média nas subestações, com exceção da estação PIN, que apresentou taxa alta.

Os resultados mostraram qualitativamente que as taxas de corrosão nas subestações PIN e ATL são altas, na subestação OSO1 ficou muito próxima do que se considera média e na subestação PAL3 de média tendendo a baixa. As altas taxas de corrosão das estações PIN e ATL devem-se à proximidade das duas instalações ao mar e à maior exposição à maresia (presença de cloretos).

A subestação de Pinhal (PIN) está localizada na região litorânea, aproximadamente a 2,5 km da orla marítima e junto à rodovia RS40, situada próximo à encosta de grandes dunas de areia. Este fato, juntamente com os constantes ventos característicos da região faz do micro-clima desta subestação o mais agressivo dos cases estudados. Este fato é também evidenciado pela maior demanda de manutenção e conseqüente substituição de partes nesta subestação. Nas amostras de aço carbono, as quais apresentaram as maiores taxas de corrosão, pode-se verificar o ataque devido à erosão na direção em que os ventos são característicos.

A subestação de Capão da Canoa (ATL) foi classificada como de agressividade muito alta para o aço e para o cobre. Como na subestação de Pinhal, as amostras de alumínio e zinco não apresentaram mudanças significativas de massa no período exposto. Esta subestação está localizada na região litorânea, aproximadamente a $0,3 \mathrm{~km}$ da orla marítima. A proximidade do mar e a conseqüente influência da maresia fazem com que esta subestação apresente altos níveis de cloreto, sendo este um dos principais agentes da corrosão. No entanto, se comparados com a subestação de Pinhal, esta subestação apresenta agressividade mais baixa.

A subestação de Osório (OSO1), localizada na região litorânea a aproximadamente 15 km da orla marítima, foi classificada como de agressividade alta para o aço e muito alta para o cobre. Esta subestação apresentou a menor agressividade das subestações estudadas no litoral. A subestação de Porto Alegre (PAL3), localizada na região urbana de Porto Alegre em uma rua de tráfego moderado, foi classificada como de agressividade média a baixa.

\subsection{Monitoramento do potencial do solo}

O valor esperado para o potencial de um sistema Zn-solo é de aproximadamente $-940 \mathrm{mV}$ em relação ao eletrodo de calomelano saturado (ECS) [1] . O ataque do zinco nas peças de aço zincado é evidenciado quando o potencial torna-se mais positivo (menos nobre). Esta alteração do valor indica que o zinco foi atacado, e o aço está em contato com o meio. No tempo de 10 meses não houve alteração significativa nos valores de potencial, indicando que o aço não foi exposto ao meio. A Tabela 3 mostra os potenciais medidos nas quatro subestações em estudo.

Tabela 3: Potenciais dos Eletrodos de Aço Galvanizado.

\begin{tabular}{c|c|c|c|c}
\hline \multirow{2}{*}{ Tempo de Ensaio } & \multicolumn{4}{|c}{ Potencial $\left(\mathrm{V}_{\text {ECS }}\right)$} \\
\cline { 2 - 5 } & PIN & ATL & OSO1 & PAL3 \\
\hline $24 \mathrm{~h}$ & $-0,940$ & $-1,048$ & $-1,045$ & $-0,900$ \\
\hline 7 meses & $-0,934$ & $-1,005$ & $-1,004$ & $-0,885$ \\
\hline 10 meses & $-0,932$ & $-0,980$ & $-0,980$ & $-0,882$ \\
\hline
\end{tabular}

\subsection{Análise química do solo}

Os resultados das análises químicas dos solos, em relação ao teor de cloreto e enxofre total, em duas datas distintas, estão sumarizados na Tabela 4.

As análises de cloreto no solo mostraram que a subestação ATL apresentou valores mais elevados que as demais estações. Este resultado já era esperado devido a sua maior proximidade do mar, cerca de 300 metros.

Para o enxofre total as análises não são conclusivas, uma vez que os valores medidos são muito baixos e a diferença entre os percentuais é insignificante. 
RIEDER, E. S.; BRUSAMARELLO, V.; BIANCHI, A.L.; BALBINOT, A.; Revista Matéria, v. 14, n. 3, pp. 1000 - 1014, 2009.

Tabela 4: Teores de Cloreto e Enxofre nos Solos das Subestações

\begin{tabular}{c|c|c|c|c}
\hline Subestação & $\begin{array}{c}\text { Teor de Cloreto } \\
\text { ppm (1) }\end{array}$ & $\begin{array}{c}\text { Teor de Cloreto } \\
\text { ppm (2) }\end{array}$ & $\begin{array}{c}\text { Teor de Enxofre } \\
\%(1)\end{array}$ & $\begin{array}{c}\text { Teor de Enxofre } \\
\%(2)\end{array}$ \\
\hline ATL & 34 & 61 & 0,03 & 0,03 \\
\hline PIN & 4 & 4 & $<0,01$ & $<0,01$ \\
\hline OSO1 & 4 & 25 & 0,01 & 0,01 \\
\hline PAL3 & 3 & 6 & 0,02 & 0,02 \\
\hline
\end{tabular}

\subsection{Resistividade do solo}

Apesar da resistividade do solo ser apenas uma das variáveis físico-químicas que podem influenciar as taxas de corrosão de metais, pode-se ter uma idéia da influência da mesma no processo. Os resultados médios obtidos são apresentados na Tabela 5.

Tabela 5: Resistividade do Solo das Subestações

\begin{tabular}{c|c}
\hline Local & $\rho(\Omega . \mathrm{m})$ \\
\hline PIN & 5141 \\
\hline ATL & 4669 \\
\hline OSO1 & 22707 \\
\hline PAL3 & 13319 \\
\hline
\end{tabular}

Quanto maior a resistividade do solo menor é a atividade corrosiva neste meio. Segundo Wranglén [23], valores de resistividade maiores que $1000 \Omega \mathrm{cm}$ implicam em agressividade baixa do solo. Os valores de resistividade encontrados indicam que a agressividade dos solos nas subestações é baixa.

Os resultados deste experimento mostram que o solo possui uma influência pequena, se comparados com a influência das condições atmosféricas. Embora os agentes agressivos estejam presentes no solo, as altas taxas de corrosão e a conseqüente agressividade do local são fortemente dependentes do ambiente de maresia.

\subsection{Análise da morfologia superficial}

As morfologias superficiais dos materiais metálicos expostos aos diversos ambientes das subestações estudadas, em tempo real, são apresentadas por tipo de material: alumínio, aço, cobre e zinco.

O alumínio, comparado aos demais metais analisados, apresentou as menores velocidades de corrosão e perdas de massa.

O alumínio, caracteristicamente, apresenta uma fina película de óxido de alumínio, $\mathrm{Al}_{2} \mathrm{O}_{3}$, formada quando exposto ao ar, que é responsável pela sua resistência à corrosão atmosférica. O processo corrosivo sobre este material, por esta razão, ocorre de forma localizada, com formação de pites, não se manifestando sobre toda a superfície. O produto de corrosão predominante é a alumina de aspecto quebradiço. Todas as amostras continham particulados (poeira) e manchas associadas à umidade. Ainda que indiretamente, o depósito de particulado se converte em um fator decisivo na corrosão por favorecer a retenção de umidade e criar condições de aeração diferencial que desestabilizam e causam ruptura localizada na película protetora de alumina. Os corpos-de-prova expostos às intempéries no litoral apresentaram estabilidade, com apenas alguns pontos de corrosão por pites. Áreas com a película de alumina totalmente quebradiça foram observadas, as quais, após ataque químico para a remoção dos produtos de corrosão, revelaram pites, Figura 2 a. As peças expostas na subestação PAL3 mostraram-se inalteradas, sem corrosão aparente, Figura 2 b. 
RIEDER, E. S.; BRUSAMARELLO, V.; BIANCHI, A.L.; BALBINOT, A.; Revista Matéria, v. 14, n. 3, pp. 1000 - $1014,2009$.

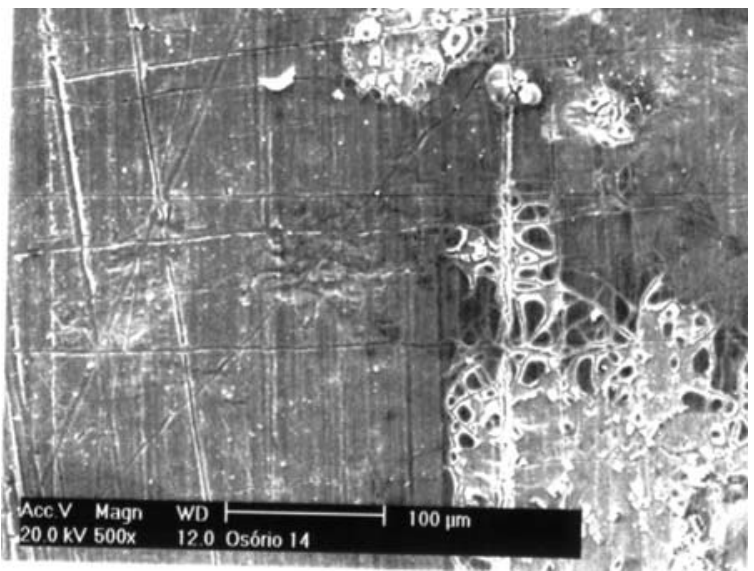

a)

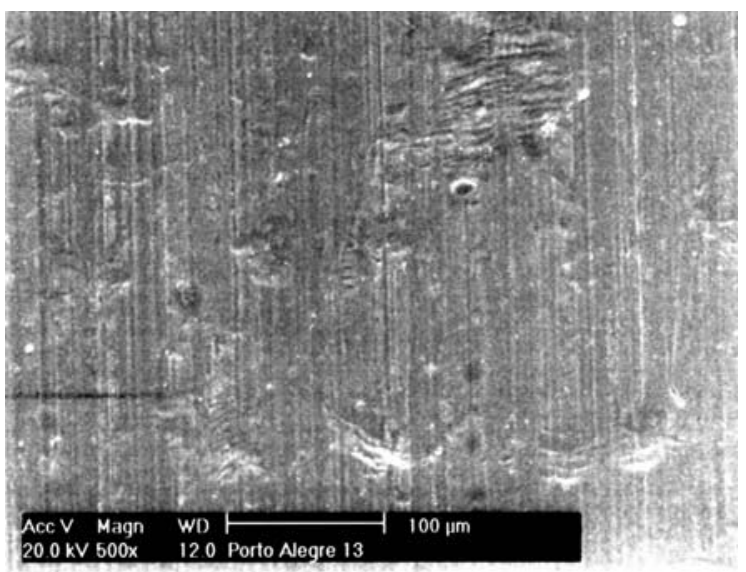

b)

Figura 2: Micrografias por MEV de peças de alumínio expostas às intempéries nas subestações: a) OSO1, b) PAL3.

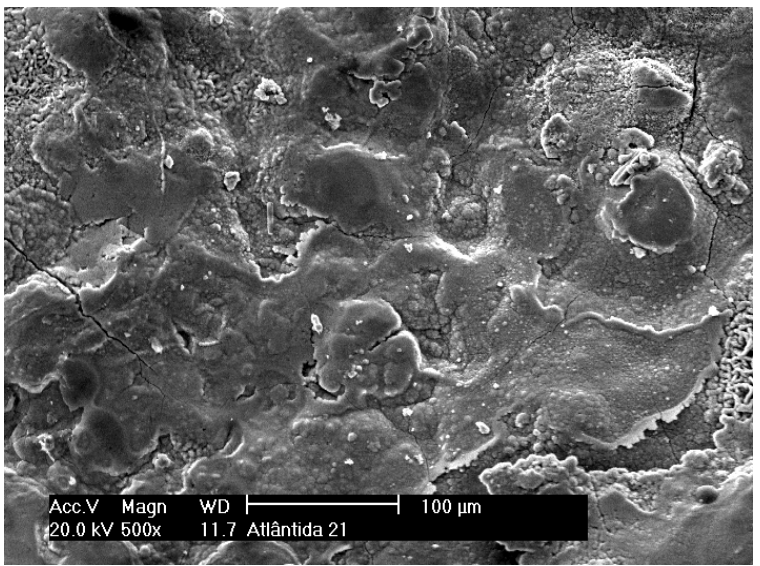

a)

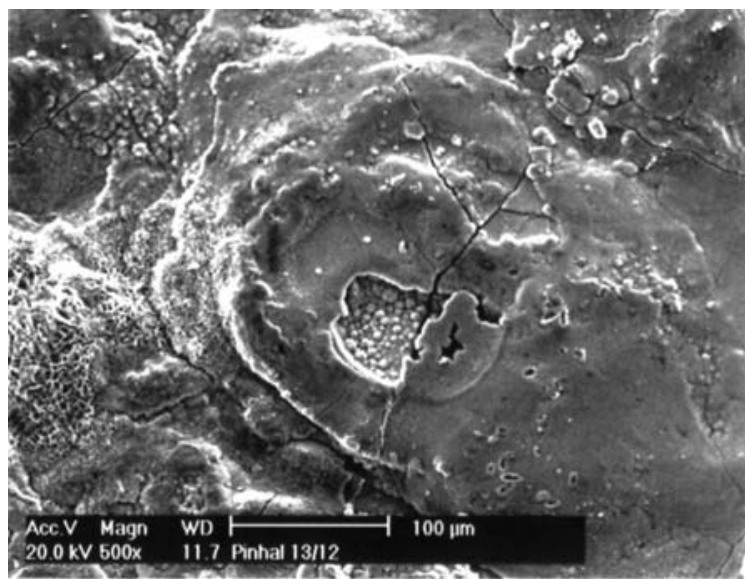

c)

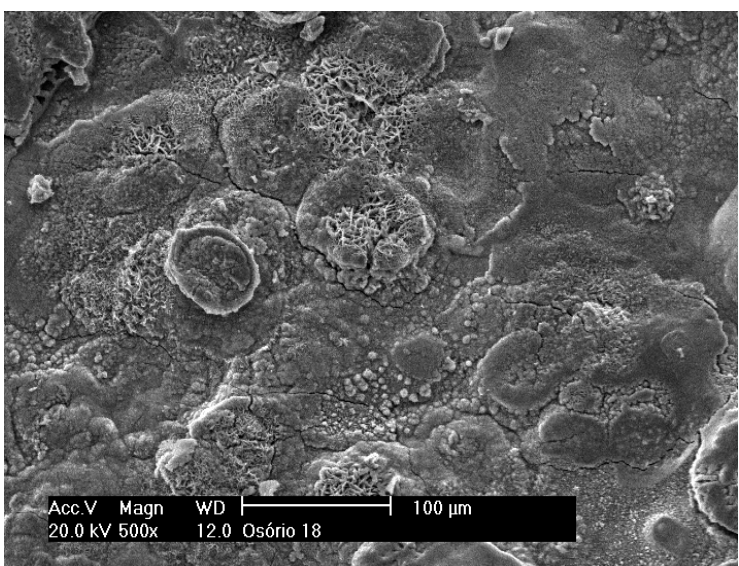

b)

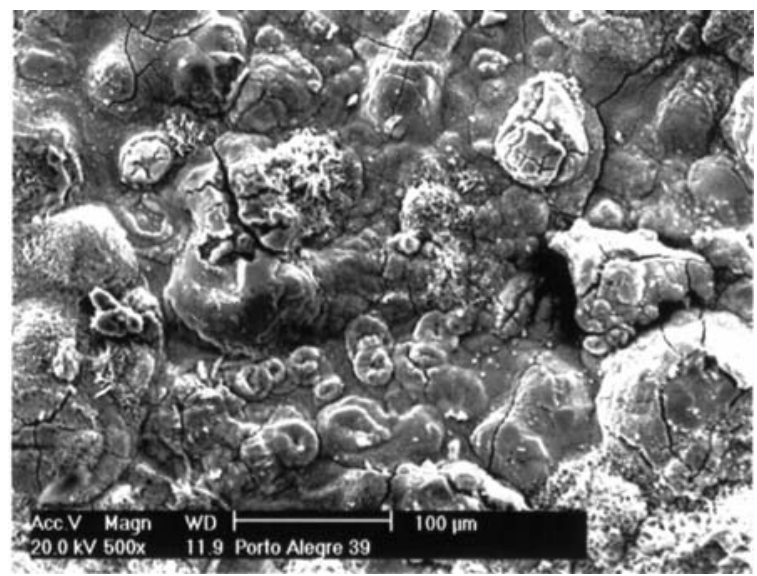

d)

Figura 3: Micrografias por MEV de peças de ferro após exposição às intempéries nas subestações: a) ATL, b) OSO1, c) PIN e d) PAL3. 
O processo corrosivo do aço, diferentemente ao do alumínio, manifesta-se sobre toda a extensão da superfície, ocorrendo perda uniforme de espessura. O processo de corrosão generalizada ocorre em materiais metálicos que não apresentam películas protetoras naturais.

De forma geral, observa-se que os produtos de corrosão do aço são semelhantes nas diversas atmosferas, Figura 3. A característica protetora do produto de corrosão em algumas atmosferas não é função primordial do tipo de óxido ou sal formado, sendo fator preponderante a sua morfologia e conseqüentemente sua cinética de formação. As peças de aço apresentaram estruturas superficiais na forma de grumos, características de produtos de óxidos de ferro.

$\mathrm{O}$ cobre e suas ligas, quando expostos à ambientes externos, recobre-se naturalmente de uma delgada película de óxido de cobre, $\mathrm{Cu}_{2} \mathrm{O}$ (cuprita), com coloração castanha, que posteriormente escurece com o tempo de exposição, devido à presença de oxigênio, que forma o CuO. Estes produtos, por serem praticamente insolúveis em água, mantêm-se sobre a superfície do metal conferindo-lhe características protetoras. Com presença de umidade e gás carbônico, $\mathrm{CO}_{2}$, a cor passa à esverdeada devido à formação dos carbonatos básicos, $\mathrm{CuCO}_{3} \cdot \mathrm{Cu}(\mathrm{OH})_{2}$ malaquita e $2 \mathrm{CuCO}_{3} \cdot \mathrm{Cu}(\mathrm{OH})_{2}$ azurita [22]. Em atmosferas marinhas, pode-se observar a formação de cloreto básico de cobre, $\mathrm{CuCl}_{2} \cdot 3 \mathrm{Cu}(\mathrm{OH})_{2}$ atacamita, de coloração esverdeada. As formações sobre a superfície do cobre são descontínuas e pouco compactas, caracterizando uma topografia rugosa e irregular. Este aspecto facilita a condensação de umidade e retenção de agentes agressores (sulfatos e cloretos) em seu interior, dificultando o arraste dos mesmos pela chuva, facilitando a formação de sais básicos. Com o tempo de exposição, a precipitação destes sais básicos sobre a microestrutura irregular da cuprita ocasiona a compactação da película dos produtos de corrosão. Esta compactação diminui a velocidade de corrosão, fornecendo uma maior proteção na superfície metálica. Os corpos-de-prova de todas as subestações estudadas apresentaram morfologia similar, Figura 4.

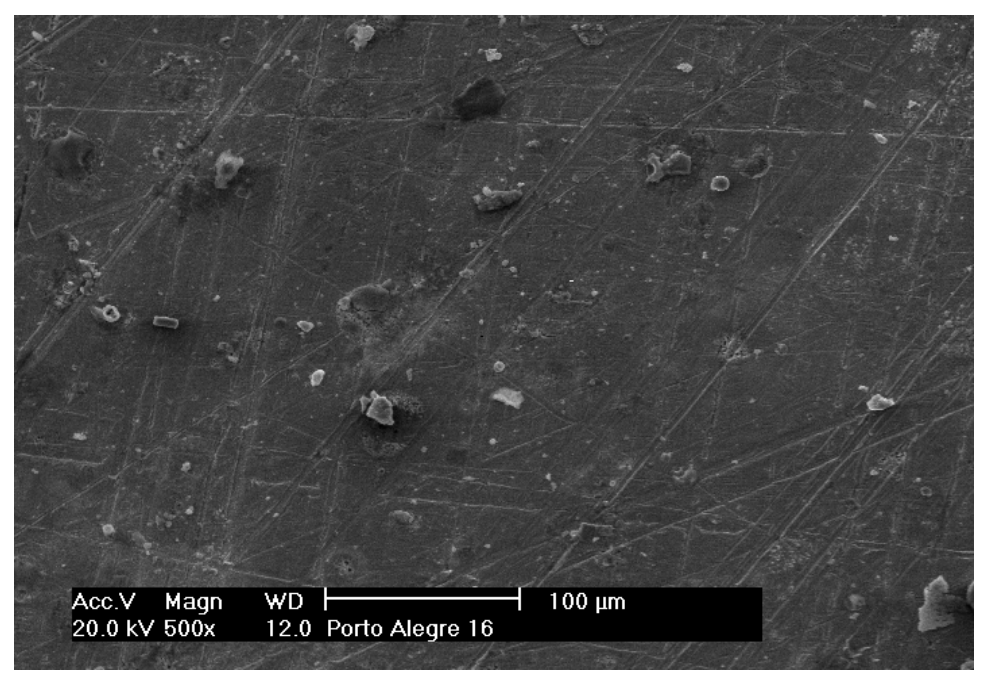

Figura 4: Micrografia representativa por MEV de cobre após exposição às intempéries na subestação PAL3.

O zinco e o aço galvanizado, quando expostos a ambientes não poluídos, formam, pela ação corrosiva, óxido de zinco, $\mathrm{ZnO}$, e/ou hidróxido de zinco, $\mathrm{Zn}(\mathrm{OH})_{2}$. Esses compostos recobrem a superfície de zinco e possuem características protetoras. O óxido de zinco apresenta aderência e não é poroso. Este óxido, sob ação do gás carbônico e umidade existente na atmosfera, pode formar o carbonato básico de zinco, insolúvel, $3 \mathrm{Zn}(\mathrm{OH})_{2} \mathrm{ZnCO}_{3}$, que em atmosferas secas e não-poluídas cobrem completamente a superfície, reduzindo o processo corrosivo. Estas características conferidas ao metal somente ocorrem em ambientes secos, pois em presença de umidade e áreas confinadas ocorre um aumento acentuado da taxa de corrosão devido à condensação de umidade saturada de ácido carbônico, atacando o metal [22].

As topografias das peças de zinco expostas na região litorânea pelo tempo de 3 meses, observadas em MEV, apresentaram morfologia similar, com ataque moderado. Já as peças expostas na subestação PAL3 apresentaram um ataque corrosivo mais agressivo, Figura 5. 


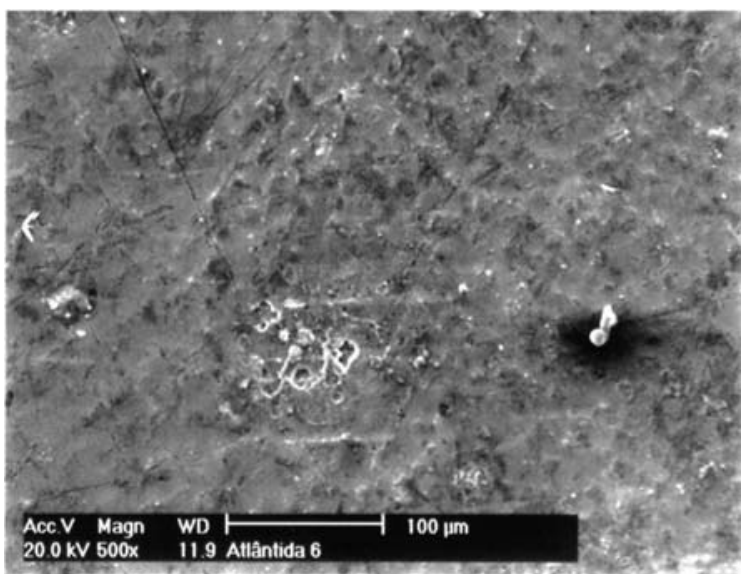

a)

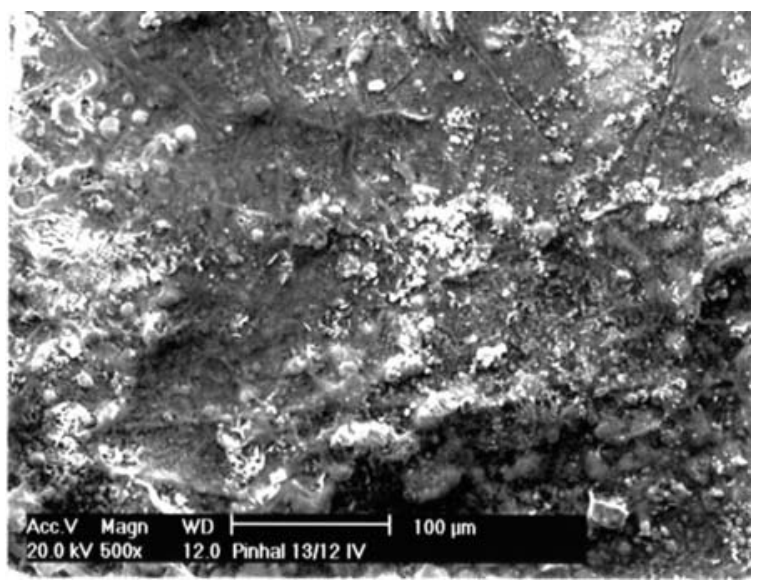

c)

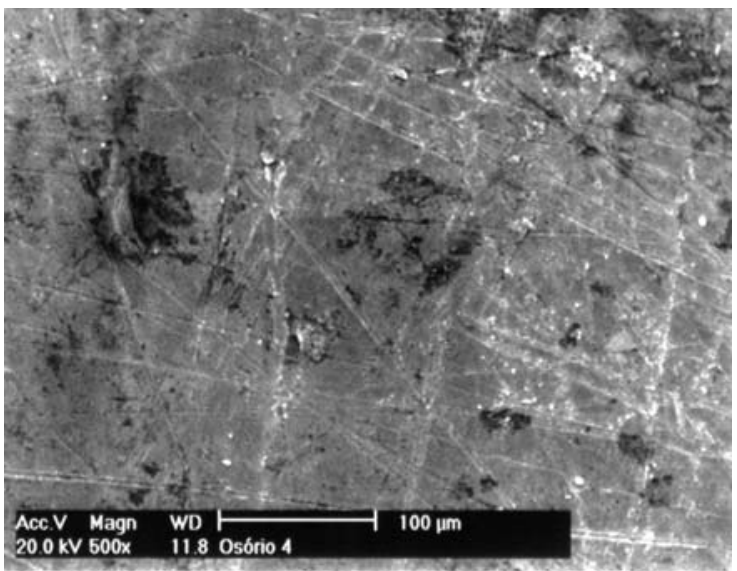

b)

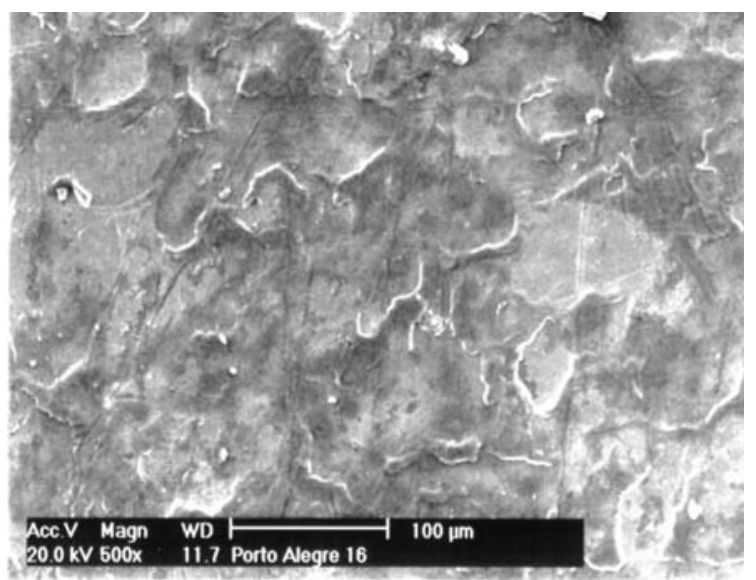

d)

Figura 5: Micrografias por MEV de peças de zinco após exposição às intempéries nas subestações: a) ATL, b) OSO1, c) PIN e d) PAL3.

\subsection{Análise química de superfície}

Os resultados das análises químicas, realizadas por Espectroscopia de Energia Dispersiva, são apresentados em espectros na Figuras 6.

Os corpos-de-prova de alumínio de todas as estações apresentaram espectros semelhantes. Um espectro típico é apresentado na Figura 6a, o qual mostra um pico de oxigênio proveniente da fina película superficial de óxido de alumínio.

Os corpos-de-prova de aço foram as que sofreram maior deterioração por processos corrosivos, resultando em superfícies com acúmulo de produtos corrosivos (carepas), Figura 7. As análises indicam que os produtos são formados por Fe e O, Figura 6 b. De acordo com estudos referenciados é sabido que o produto corrosivo formado na superfície do aço é constituído de uma mistura de óxidos e hidróxidos de ferro em estrutura espinel [8]. O cloreto, presente em atmosferas marinhas, catalisa o processo corrosivo do aço, porém nos produtos da corrosão este íon não é identificado em análise química por não formar produtos insolúveis com o metal base. O íon tende a ser lavado da superfície com as condensações.

Os espectros de energia dispersiva para as amostras de cobre, Figura 6 c, como para os demais metais, também mostraram picos característicos de oxigênio, o que, conforme já mencionado anteriormente, é devido à formação de óxidos. As amostras de cobre expostas no litoral apresentaram picos característicos de cloro. Estes picos concordam com as observações anteriores, que é possível a formação de cloretos básicos de cobre $\left[\mathrm{CuCl}_{2} \cdot 3 \mathrm{Cu}(\mathrm{OH})_{2}\right.$ atacamita] em atmosferas marinhas.

Os espectros do zinco também apresentaram picos correspondentes do oxigênio, sendo a amostra proveniente da subestação de Pinhal, PIN, a que apresentou maior concentração deste elemento, o que pode 
RIEDER, E. S.; BRUSAMARELLO, V.; BIANCHI, A.L.; BALBINOT, A.; Revista Matéria, v. 14, n. 3, pp. 1000 - 1014, 2009.

indicar que o processo de oxidação nesta amostra foi mais marcante que nas amostras do mesmo metal nas demais subestações, Figura 6 d.

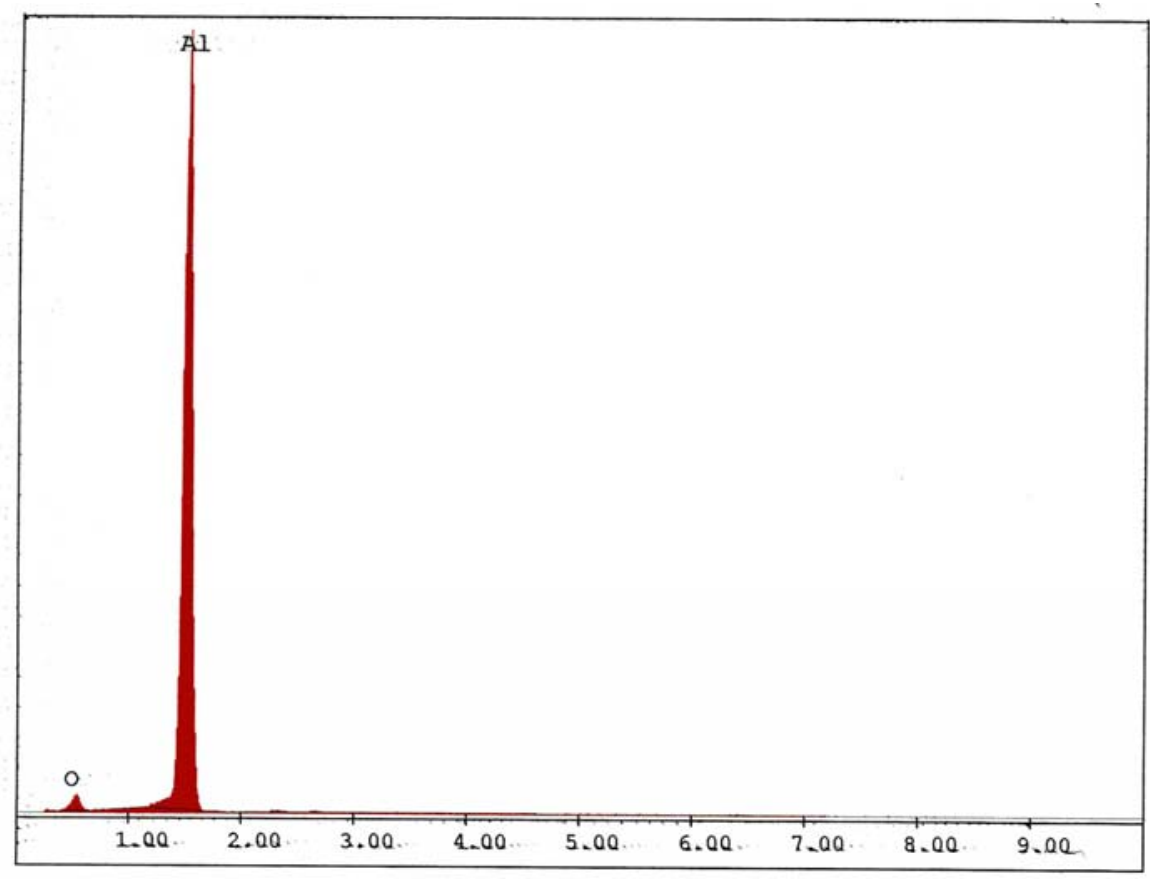

a)

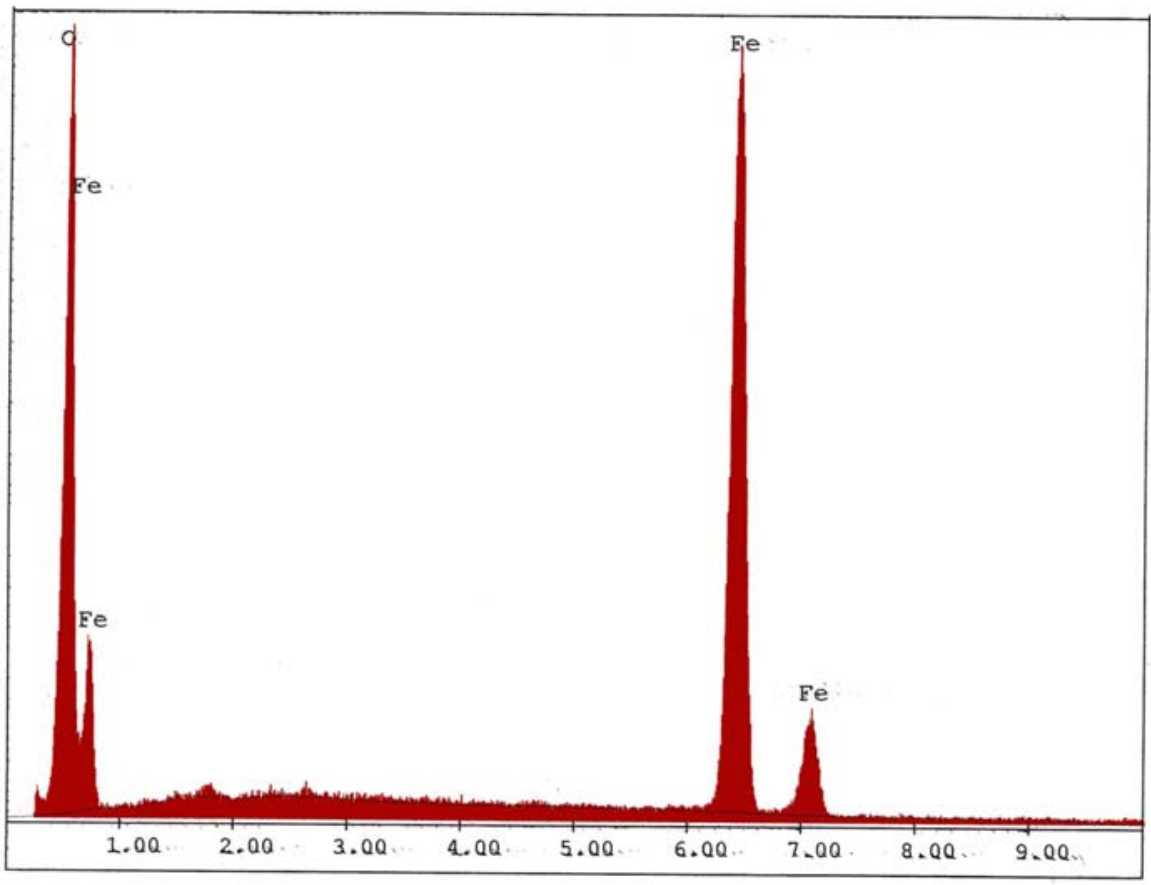

b) 
RIEDER, E. S.; BRUSAMARELLO, V.; BIANCHI, A.L.; BALBINOT, A.; Revista Matéria, v. 14, n. 3, pp. 1000 - $1014,2009$.

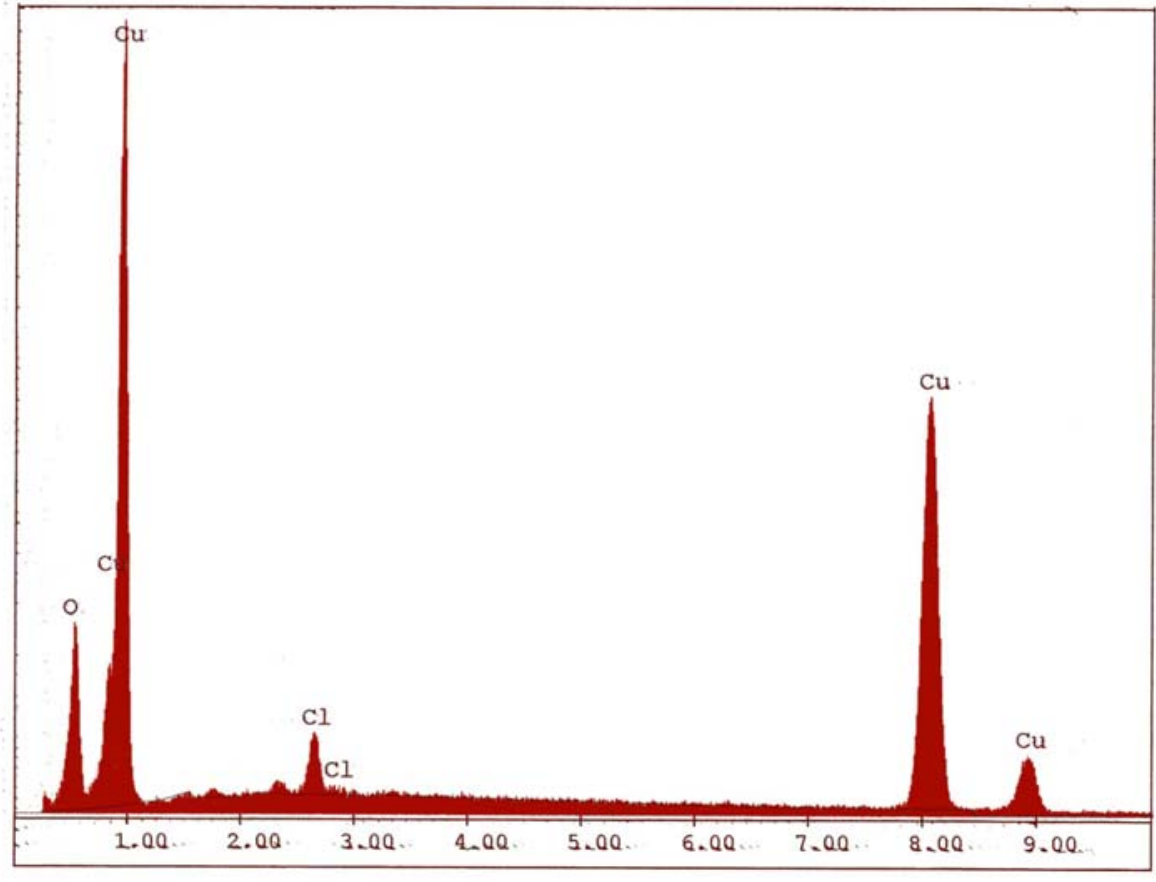

c)

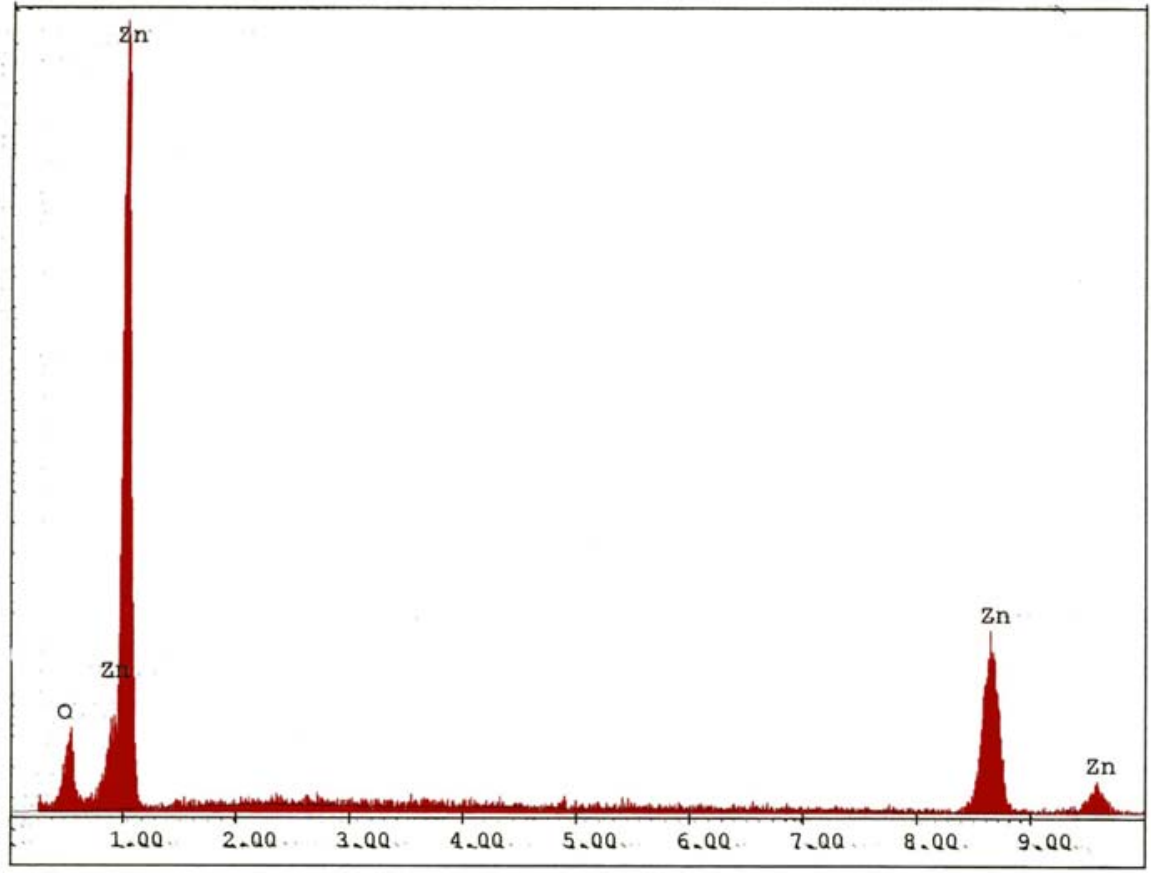

d)

Figura 6: Espectros de Energia Dispersiva típicos dos corpos-de-prova após exposição às intempéries nas subestações: a) alumínio, b) aço, c) cobre e d) zinco 


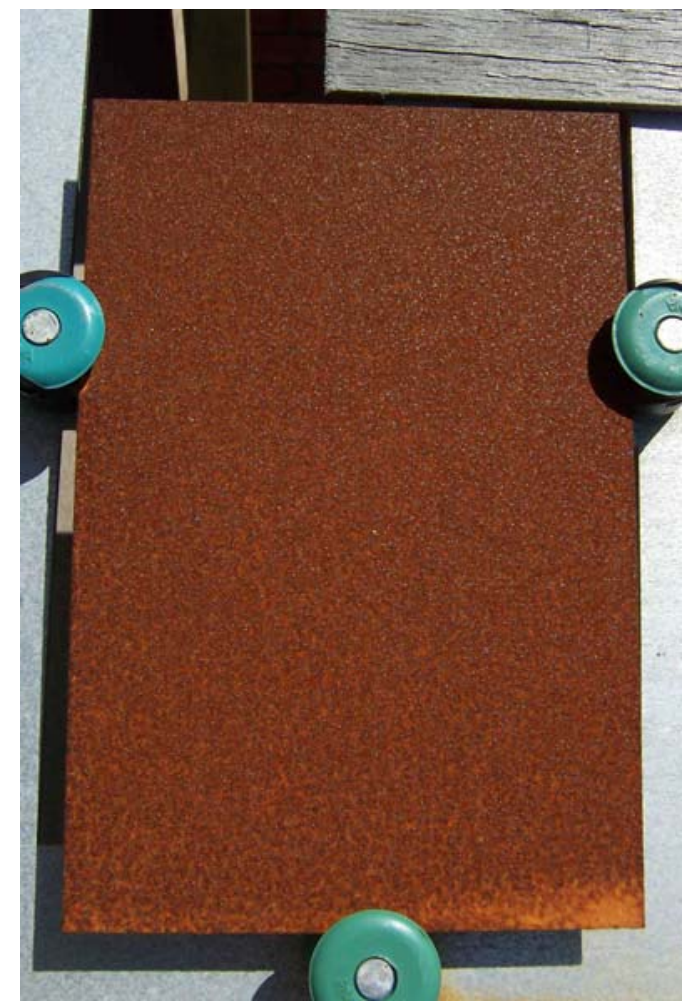

Figura 7: Peça de aço após exposição às intempéries no litoral, mostrando carepa formada por produtos corrosivos.

Dependendo do material metálico, do meio corrosivo e dos poluentes presentes, os processos corrosivos serão mais rápidos e os produtos de corrosão apresentarão características inerentes a cada tipo de atmosfera e de material metálico.

A ação corrosiva da atmosfera depende fundamentalmente de fatores como: umidade relativa, substâncias poluentes (particulados e gases), temperatura e tempo de permanência do material no meio, bem como de fatores climáticos, como intensidade e direção dos ventos, variações cíclicas de temperatura e umidade, chuvas e radiação ultravioleta.

A umidade é um fator preponderante na ação do processo corrosivo. Pois, mesmo em presença de cloretos em teores similares aos encontrados em ambiente marinho, o processo de corrosão somente é significativo em ambientes com umidade relativa elevada.

A presença de partículas sólidas, como é o caso da areia em ambientes marinhos, promove o processo corrosivo de forma indireta. A deposição deste material não-metálico sobre a superfície não ataca diretamente o material metálico, porém cria condições para o mecanismo de corrosão por aeração diferencial. Neste processo, o material é atacado localmente sob o particulado (com presença reduzida de oxigênio). Com a presença de particulados, também pode haver a retenção de umidade, acelerando o processo corrosivo. Em ambientes marinhos a maior ação corrosiva deve-se à deposição de névoa salina contendo sais de cloreto.

\section{CONCLUSÃO}

Os resultados mostraram que as taxas de corrosão nas subestações PIN e ATL são altas, na subestação OSO1 ficou muito próxima do que se considera média e na subestação PAL3 de média tendendo a baixa. A subestação de Pinhal (PIN) foi a que apresentou a maior agressividade atmosférica dentre as subestações estudadas, e a subestação de Capão da Canoa (ATL) apresentou a segunda maior agressividade. Houve significativa perda de massa no aço e no cobre, principalmente nas subestações litorâneas. Já para o zinco e o aço galvanizado, a corrosão foi mais expressiva em Porto Alegre, região urbana sem presença de maresia.

A alta resistividade do solo nas subestações estudadas implica em agressividade baixa do solo. Embora os agentes agressivos cloreto e enxofre estejam presentes no solo, as altas taxas de corrosão no litoral e a consequente agressividade do local dependem expressivamente da maresia. O solo possui uma influência pequena, se comparados com a influência das condições atmosféricas. 
Em todas as subestações, o monitoramento do potencial no eletrodo de aço galvanizado foi pouco conclusivo para o tempo de exposição.

Com os resultados das análises e observações realizadas nos materiais metálicos expostos às intempéries nas subestações, pode-se concluir que a subestação de Pinhal é a que apresenta as condições mais favoráveis ao processo corrosivo de todas as subestações avaliadas, seguidas pelas subestações de Capão da Canoa e Osório. Com estas conclusões, fica evidente que os procedimentos e precauções em relação à corrosão dos componentes metálicos das subestações expostas a condições extremas de agressividade, como em Pinhal, não podem ser os mesmos que os adotados na região urbana.

\section{AGRADECIMENTOS}

Os autores agradecem a Companhia Estadual de Energia Elétrica pelo suporte financeiro e ao Centro de Microscopia Eletrônica e Microanálise da ULBRA pelas imagens de microscopia eletrônica.

\section{BIBLIOGRAFIA}

[1] BRUSAMARELLO, V.J., HUDSON, J.L., SCULLY, J.R., LUNT, T., MIKHAILOV, A.S, "Spatial interactions among localized corrosion sites”, Journal of Electrochemical Society, v. 149, n. 5, pp. B163 - B173, 2002.

[2] RIEDER, E.S., "The passivity of a super duplex stainless steel”, $P h D$ Thesis - The University of Birmingham, UK, 1997.

[3] MONTENEGRO, I.N.S, FILGUEIRA, M.R.A., NETO J.N.A., "Corrosão atmosférica no Estado do Ceará”, In: Anais do II Congresso de Inovação Tecnológica em Energia Elétrica: Corrosão, v. 1, pp. 61-66, 2003.

[4] MELONI, A.E.M., MORGENSTERN JR, A., MELLO, D.R., MAURÍCIO, M.R.D. GARCIA, R.W.S., "Desenvolvimento de novo isolador antipoluição com perfil aberto", In: Anais do II Congresso de Inovação Tecnológica em Energia Elétrica: Corrosão, pp. 67-72, 2003.

[5] MELLO, D.R., COUTINHO, I.M., "Pesquisa de tipos de isoladores adequados às condições ambientais do Espírito Santo", In: Anais do II Congresso de Inovação Tecnológica em Energia Elétrica: Corrosão, pp. 73-78, 2003.

[6] KENNY, E.D., CRUZ, O.M., SILVA, J.M., LAZARIS, J., NOVAES JR., J.V., SICA, Y.C., RAVAGLIO, M., MENDES, P.R., MENDES, J.C., "O impacto da poluição atmosférica sobre a rede aérea de distribuição de energia da Ilha de São Luis”, In: Anais do $7^{\circ}$ COTEQ, artigo 131, 2003.

[7] MORCILLO, M., ALMEIDA, E., ROSALES, B., URUCHURTU, J., MARROCOAS, M., Corrosión y protección de los metales en las atmosferas de iberoamericanas, Parte I Mapas de Iberoamérica de Corrosividad Atmosférica (proyecto MICAT, XV.1/CYTED), Madrid: Ed Gráficas Salué S. A., 1999.

[8] KAJIMOTO, Z.P., SIQUEIRA, F.J.S., ALMEIDA, N.L. "Estudo do comportamento de materiais metálicos expostos na atmosfera do Estado de São Paulo”, Tratamento de Superfície (3 partes), São Paulo, pp. 25-37, Fev./Mar. 1990, pp. 16-25, Abr./ Maio. 1990, pp. 27-38, Jun / Jul, 1990.

[9] FRAGATA, F.L., SERRA, E.T., ARAÚJO, M., "Desempenho de materiais com e sem revestimentos protetores em estação de corrosão atmosférica em ambiente marinho”, In: $13^{\circ}$ SENACOR, pp. 198-208, Rio de Janeiro, 1986.

[10] DEAN, S.W., "Atmospheric corrosion after 80 years of study”, Materials Performance, pp. 9-11, Jul, 1987.

[11] TOWNSEND, H.E., BORZILLO, R., "Twenty - year atmospheric corrosion tests of hot-dip coated sheet steel”, Materials Performance, pp. 37-41, July, 1987. 
RIEDER, E. S.; BRUSAMARELLO, V.; BIANCHI, A.L.; BALBINOT, A.; Revista Matéria, v. 14, n. 3, pp. 1000 - 1014, 2009.

[12] KAJIMOTO, Z.P. et al., Corrosão atmosférica de metais no estado de São Paulo, v. 57, IPT, São Paulo, 1991.

[13] INTERNATIONAL ORGANIZATION OF STANDARDIZATION, "Corrosion of metals and alloys Corrosivity of atmospheres - Determination of corrosion rate of standard specimens for the evaluation of corrosivity”, ISO 9226:1992 (E), 1992.

[14] INTERNATIONAL ORGANIZATION OF STANDARDIZATION, "Corrosion of metals and alloys Removal of corrosion products from corrosion test specimens”, ISO 8407:1991(E), 1991.

[15] INTERNATIONAL ORGANIZATION OF STANDARDIZATION, "Metals and alloys - Atmospheric corrosion testing - General requirements for field tests”, ISO 8565:1992 (E), 1992.

[16] INTERNATIONAL ORGANIZATION OF STANDARDIZATION, "Corrosion of metals and alloys Corrosivity of atmospheres - Classification”, ISO 9223:1992 (E), 1992.

[17] INTERNATIONAL ORGANIZATION OF STANDARDIZATION, "Corrosion of metals and alloys Corrosivity of atmospheres - Guiding values for the corrosivity categories”, ISO 9224:1992 (E), 1992.

[18] INTERNATIONAL ORGANIZATION OF STANDARDIZATION, "Corrosion of metals and alloys Corrosivity of atmospheres - Measurement of pollution”, ISO 9225:1992 (E), 1992.

[19] INTERNATIONAL ORGANIZATION OF STANDARDIZATION, "Corrosion tests in artificial atmospheres - Salt spray tests”, ISO 9227:1990(E),1990.

[20] CHARLTON, R.S., HANCK, J.A., MEYER JR, F.H., KORB, L.J., ASM Handbook , Ninth Edition, Metals Handbook, v. 13, $4^{\circ}$ ed., 1992.

[21] ROZENFELD, I.L., Atmospheric corrosion of metals, NACE, Houston.

[22] GENTIL, V., Corrosão, 2ª ed., Rio de Janeiro, Guanabara dois, 1982.

[23] WRANGLÉN, G., An introduction to corrosion and protection of metals, Institut för Metallshkydd, Stockholm, 1972. 